\title{
Use of an organometallic palladium oxazoline catalyst for the hydrolysis of methylparathion
}

Mieock Kim, Qiancai Liu, and François P. Gabbai**

Chemistry Department, Texas A\&M University, 3255 TAMU, College Station, TX 77843-3255

\section{SUPPLEMENTARY INFORMATION}




\section{Kinetic data}

Dependencies of $k_{\mathrm{obs}}$ for the hydrolysis of methylparathion catalyzed by $\mathbf{1}$ at $\mathrm{pH} 9$ and $\mathrm{pH} 10$ $\left(0.006 \mathrm{M}\right.$ CHES buffer, $\left.25^{\circ} \mathrm{C}\right)$. $[\mathbf{P d}]=2 \times[\mathbf{1}]$

Dependence on the concentration of methylparathion; $[\mathbf{P d}]=4.02 \times 10^{-6} \mathrm{M}$.
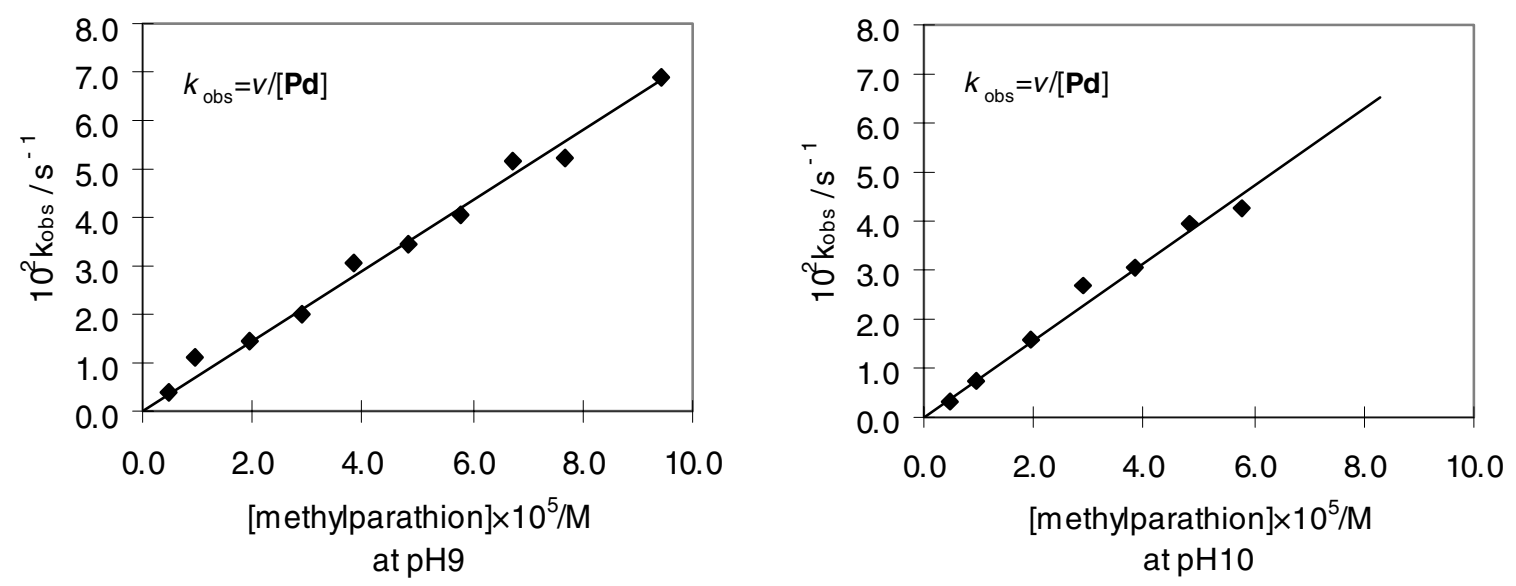

Dependence on the concentration of $\mathbf{1}$; [methylparathion] $=1.92 \times 10^{-5} \mathrm{M}$.
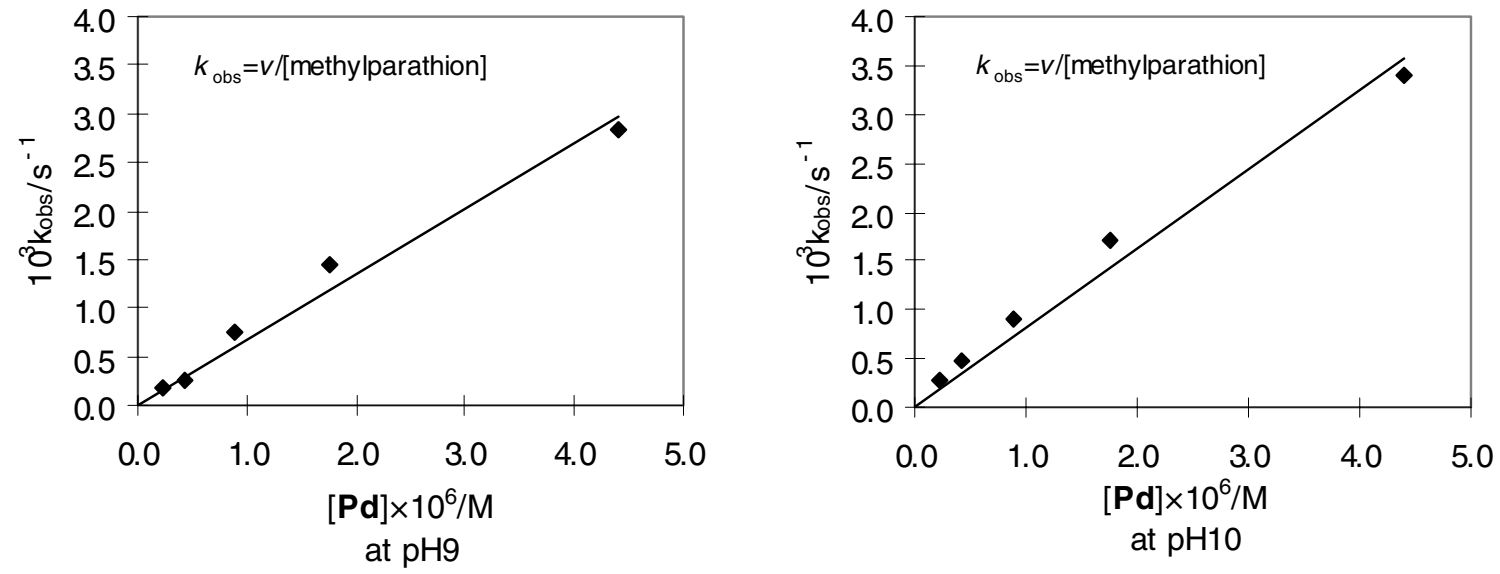


\begin{tabular}{cccc}
\hline [methylparathion $(\mathrm{M})$ & {$[\mathbf{P d}]_{\text {added }}(\mathrm{M})$} & \multicolumn{2}{c}{ Initial rate $($ Absorbance/s) } \\
$\mathrm{pH}$ & $\mathrm{pH} 10$ \\
\hline $1.92 \times 10^{-5}$ & $2.26 \times 10^{-7}$ & $5.48 \times 10^{-5}$ & $9.19 \times 10^{-5}$ \\
& $4.27 \times 10^{-7}$ & $8.82 \times 10^{-5}$ & $1.54 \times 10^{-4}$ \\
& $8.80 \times 10^{-7}$ & $2.47 \times 10^{-4}$ & $2.98 \times 10^{-4}$ \\
& $1.76 \times 10^{-6}$ & $4.75 \times 10^{-4}$ & $5.57 \times 10^{-4}$ \\
& $4.40 \times 10^{-6}$ & $9.29 \times 10^{-4}$ & $1.11 \times 10^{-3}$ \\
\hline
\end{tabular}

$4.4 \times 10^{-5} \mathrm{M}$ solution of 1 in dioxane, $0.278 \mathrm{~mL}$ of methylparathion solution $\left(2.42 \times 10^{-4} \mathrm{M}\right)$ in $\mathrm{H}_{2} \mathrm{O}, 2 \mathrm{~mL}$ of CHES buffer solution $(10 \mathrm{mM})$, total volume $3.5 \mathrm{~mL}$.

\begin{tabular}{|c|c|c|c|}
\hline \multirow{2}{*}[\mathbf{Pd}]{$_{\text {added }}(\mathrm{M})$} & \multirow{2}{*}[\text{methylparathion}]{$(\mathrm{M})$} & \multicolumn{2}{|c|}{ Initial rate $($ Absorbance/s) } \\
\cline { 3 - 4 } & & $\mathrm{pH} 9$ & $\mathrm{pH} 10$ \\
\hline $4.02 \times 10^{-6}$ & $4.84 \times 10^{-6}$ & $2.83 \times 10^{-4}$ & $2.32 \times 10^{-4}$ \\
\hline & $9.61 \times 10^{-6}$ & $7.53 \times 10^{-4}$ & $5.16 \times 10^{-4}$ \\
\hline & $1.92 \times 10^{-5}$ & $9.88 \times 10^{-4}$ & $1.09 \times 10^{-3}$ \\
\hline & $2.88 \times 10^{-5}$ & $1.38 \times 10^{-3}$ & $1.83 \times 10^{-3}$ \\
\hline & $3.84 \times 10^{-5}$ & $2.09 \times 10^{-3}$ & $2.10 \times 10^{-3}$ \\
\hline & $4.81 \times 10^{-5}$ & $2.36 \times 10^{-3}$ & $2.69 \times 10^{-3}$ \\
\hline & $5.77 \times 10^{-5}$ & $2.77 \times 10^{-3}$ & $2.90 \times 10^{-3}$ \\
\hline & $6.74 \times 10^{-5}$ & $3.52 \times 10^{-3}$ & \\
\hline & $7.70 \times 10^{-5}$ & $3.57 \times 10^{-3}$ & \\
\hline & $9.41 \times 10^{-5}$ & $4.72 \times 10^{-3}$ & \\
\hline & \multicolumn{3}{|}{} \\
\hline
\end{tabular}

$2.42 \times 10^{-4} \mathrm{M}$ solution of methylparathion in $\mathrm{H}_{2} \mathrm{O}, 0.160 \mathrm{~mL}$ of solution of $1\left(4.4 \times 10^{-5} \mathrm{M}\right)$ in dioxne, $2 \mathrm{~mL}$ of CHES buffer solution $(10 \mathrm{mM})$, total volume $3.5 \mathrm{~mL}$.

\begin{tabular}{|c|c|c|}
\hline & $\mathrm{pH} 9$ & $\mathrm{pH} 10$ \\
\hline $\mathrm{k}_{2}$ in $\mathrm{M}^{-1} \mathrm{~s}^{-1}$ & $726 \pm 30$ & $792 \pm 47$ \\
\hline
\end{tabular}

Rate law: $\mathrm{v}=\mathrm{k}_{2}[\mathbf{P d}][$ methylparathion] with $[\mathbf{P d}]=2 \times[\mathbf{1}]$ 
Time evolution of the absorbance at $400 \mathrm{~nm}$ resulting from the release of $p$-nitrophenol in the reaction of methylparathion $\left(3.84 \times 10^{-5} \mathrm{M}\right)$ in the presence of $\mathbf{1}\left(2.01 \times 10^{-6} \mathrm{M}\right)$ at $\mathrm{pH} 9(\mathrm{CHES}$ $10 \mathrm{mM})$.

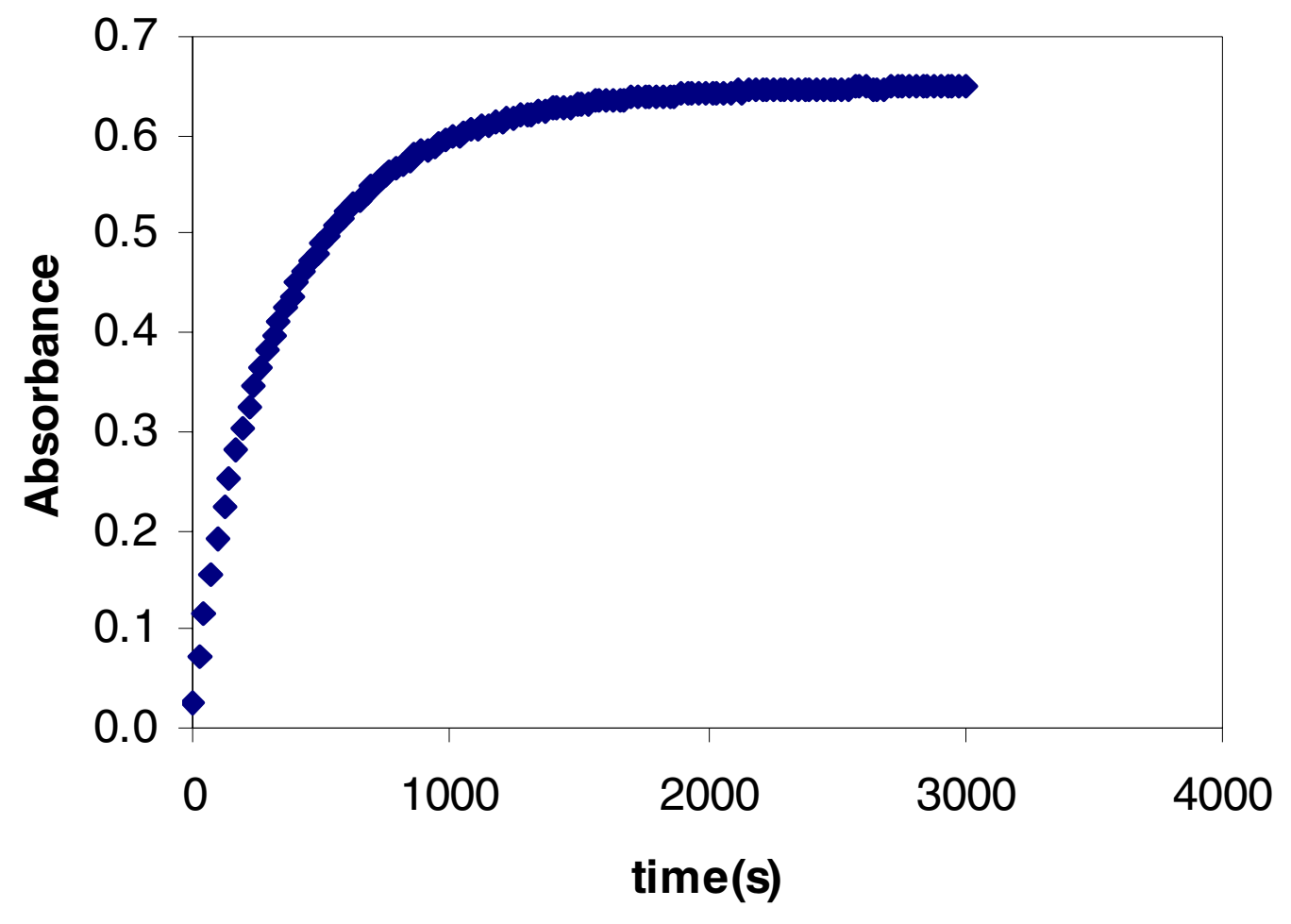




\section{CD spectroscopy}

CD spectra of a solution of $\mathbf{1}$ and methylparathion recorded at $\mathrm{t}=0,10,20,40,60,75,90,120$, 180, 210, 240 and 300 minutes.

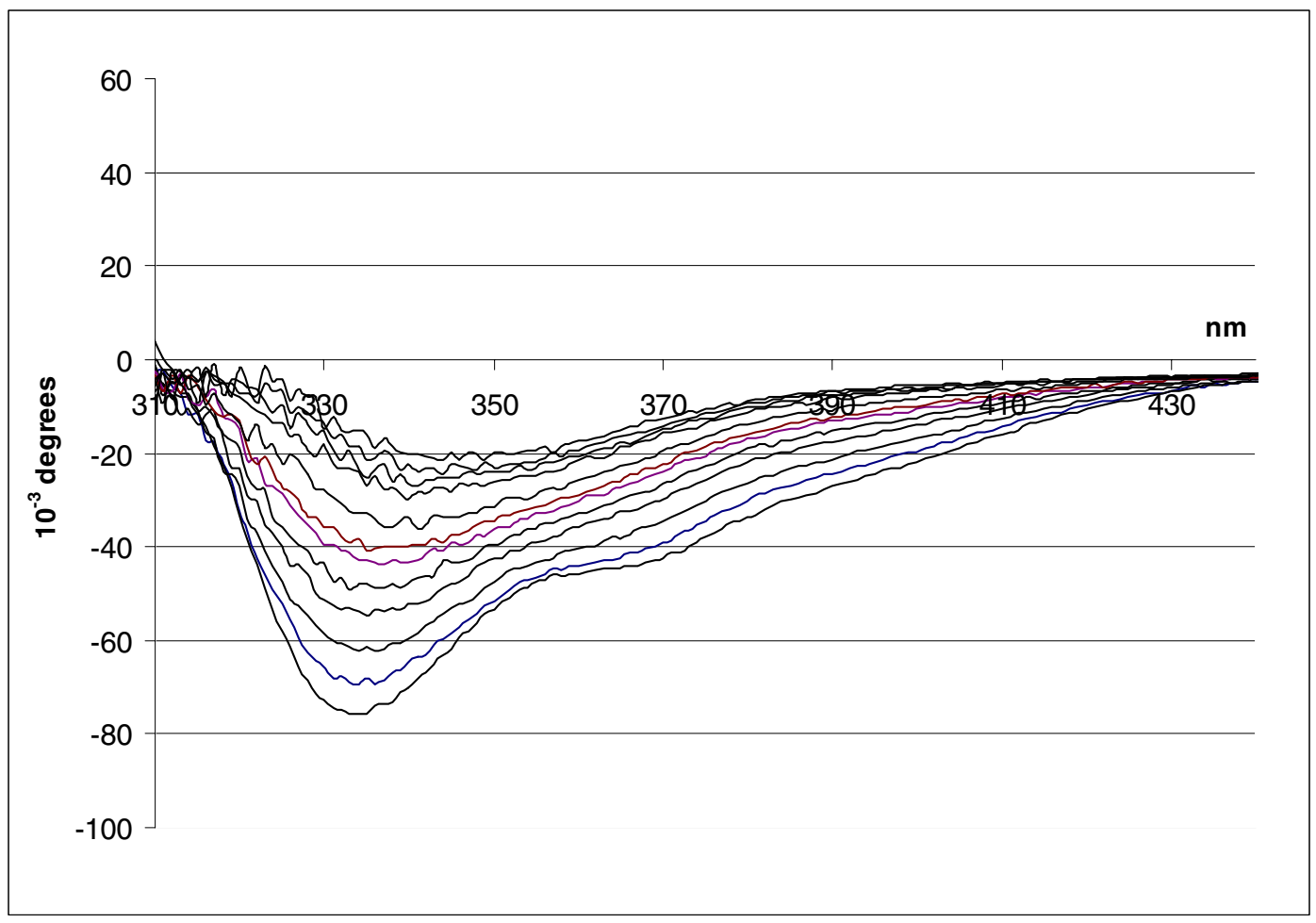

Units: $\mathrm{x}$ axis: $\mathrm{nm}, \mathrm{y}$ axis $10^{-3} \times^{\circ}$

Experimental details: A dioxane solution containing of $1([\mathbf{1}]=1.09 \mathrm{mM})$ and methylparathion ([methylparathion] $=2.17 \mathrm{mM}$ ) was palced in a cuvette (pathlength $=0.1 \mathrm{~cm}$ ). The reaction was initiated by addition of 10 equivalents of water. The CD spectrum of the solution was recorded at regular interval. 